Taking Direction: new dramaturgies of science from the Splice Symposium and Performing Science.

\title{
Alex Mermikides
}

The publication of the first of these two special issues on 'New Directions in Science and Theatre' preceded two significant UK-based conferences that also dealt with intersections between science and performance. The Splice Symposium was presented by the Chimera Network at the University of Notre Dame's London Centre in November 2013 and Performing Science at the University of Lincoln in April 2014. Splice took as its starting point correspondences between the radical shift to postclassical science and what Campos describes as 'the fundamental instability of dramatic forms shaped by the crisis of meta-narratives and of the classic Aristotlean model' $(2013,299)$. Its inclusion of science-engaged music and sound-work, as well as performance practices, on the programme, enabled a particular emphasis on artistic, as well as science-arts, interdisciplinarity which, as I will demonstrate in a moment, feeds into key debates raised by the first 'New Directions' special issue.

Performing Science offered an ambitious comprehensive mapping of what is now a broad field characterised by productive, if occasionally spiky, inter-generational debates. Thus, its delegates featured a number of those who appeared in the original 'science and theatre' special issue of Interdisciplinary Science Reviews in 2002, notably Carl Djerassi, Robert Friedman and Michael Frayn. And we heard from scholars and artists whose thinking aligns more closely with the scope of the current special issues in their consideration of the 'performative' as well as textual elements of science-engaged theatre, and of performance forms beyond the 'classic Artistolean model'. A paper by our editor Carina Bartleet analysing Rona Munro's 'space plays' was built upon a far-sighted understanding of how contemporary science-engaged performance often operates between the 'science-in-theatre' mode of the first generation, and the post-dramatic. As she points out in relation to Analogue's 2410 Objects, such work may draw on aspects of the 'devised and intermedial' without entirely decentring 'narrative or plot..[and] the potential for exposition and narrative closure' (Bartleet, 2013, 352).

These debates provide the backdrop for this short article, which, rather than offering conventional conference reports, focusses on how these questions of dramaturgical form are reflected in a handful of projects featured at the Splice Symposium. In so doing, I draw on two articles from issue one. Firstly, Vanden Heuvel's 'The Acceptable Face of the Unintelligible' enables an analysis of the way in which sound 'meddles, muddles, mangles and messes with the message' $(2013,375)$ in two productions presented at the Symposium. Thereafter, I focus on how biomedical science is 'mediated' in these and other Wellcome Trust funded projects, thereby extending a discussion opened within Campos' 'Science in Contemporary British Theatre'.

\section{New Direction 1: the aural, the intermedial and the communication of science}

The aural dimension of performance practice, and intertwinings between theatre and music, are the subject of a growing area of scholarship ${ }^{1}$ that may usefully inform questions relating to contemporary science plays. What I consider here is sound - defined by Frances Dyson as 'the immersive medium par excellence' $(2009,4)$ - as a component of the 'inter-medial science play': that is, how it can 'interfere and resonate' (Vandel Heuvel, 2013, 375) with other theatrical elements to create the effect of wonder that Vanden Heuvel so eloquently describes: the simultaneously bleak and pleasurable sensation of being at the edge of understanding.

\footnotetext{
${ }^{1}$ Kendrick and Roesner 2011 considers the former, and Roesner and Rebstock 2013 the latter.
} 
Going Dark ${ }^{2}$, a tale of a planetarium narrator diagnosed with a degenerative sight condition, employs surround sound and lighting to shift the audience's sensory engagement from the visual to the aural. By creating moments of black-out in which we are entirely reliant on listening, the audience shares the protagonist's struggle to come to terms with the onset of blindness. A demonstration of optical illusions also exposes the failure of our eyes to construct a reliable picture of the world. In Melanie Wilson's Autobiographer ${ }^{3}$, the sound design increasingly displaces the voices of the four performers who represent the central character at different ages, while acoustic effects create the illusion of a shifting space. Through this, Wilson suggested in her presentation, we get 'a more visceral, embodied experience of what it might be like to live with dementia' ${ }^{4}$, with its disruptions to autobiographical memory and a sense of self. In both cases, the imagined visual and spatial environments conjured by sound (what another Splice contributor, Tony Myatt, called 'spatiality within the aural') conflict with our visual sense. Thus, the audience in placed in a 'position of indeterminacy and instability in relation to how information is processed' (Vanden Heuval, 2013). Indeed, these and other contributors to the Symposium were indebted to the seminal work of the late Richard Gregory on sensory perception.

Thus far then, these projects seem to ally with Vanden Heuvel's characterisation of the intermedial science play. Except that it could be argued that these sonic intermedial effects are not in fact employed in the conveyance of scientific ideas as such, but rather as a way of representing an experience of pathology. Indeed scientific information about these pathologies (retinis pigmentosa for Going Dark, and dementia for Autobiographer) does not feature explicitly within the productions. Where scientific ideas are explicitly communicated it is through an essentially classical dramatic format: Going Dark is built around a series of planetarium presentations by the protagonist. This science is often 'wondrous': in spanning astronomy, astrophysics and visual perception, the production makes an elegant link between 'how the eye and the brain make sense of the world' and 'how one makes sense of the world and the cosmos', as co-director Mark Espiner described. However, I would question whether its means of communication could be described as intermedial. Rather, the device of having a character deliver a lecture ${ }^{5}$, however skilfully and thoughtfully employed, seems more aligned with the Carl Djerassi's strategy of 'smuggling in' scientific fact something that Vandel Heuvel defines as distinct from the inter-medial play. Indeed Espiner inadvertently echoed Djerassi's term in his presentation when he described 'the challenge of how to smuggle [the science] into the show without losing its accuracy'.

Other than through the spoken word, how then might sound be employed to convey scientific ideas? Two further possibilities for integrating sound and science were illustrated by Symposium contributors. Simon Park and Tony Myatt both presented projects wherein recording technologies allowed the listener access to rarely heard sounds: the disintegration of fossilised shell under acid (wherein changes in sound reveal aspects of its internal structure and composition) for the former, and an annual gathering a whales (which provide key information about whale behaviour and culture) was among the projects introduced by the latter. Myatt's work with the T-B A21 Academy, a research vessel carrying both artists and scientists work involved in oceanic research has led to

\footnotetext{
${ }^{2}$ http://fueltheatre.com/projects/going-dark

${ }^{3}$ http://www.melaniewilson.org.uk/projects/autobiographer

${ }^{4}$ Recordings of all presentations cited are available at chimeranetwork.org/splice

${ }^{5}$ For a discussion of the performance of scientific lectures, see Knight 2002. The character of Max in Going Dark could be usefully analysed in terms of Campos' discussion of the trope of the observer character 'attempting to understand a human situation through rational analysis' $(2013,299)$
} 
several arts projects employing sound thus gathered in a scientific context ${ }^{6}$. Other projects exploited the capacity of sound to embed, or be embedded within, scientific data through processes of datasonification. Carla Scaletti's score for Gilles Jobin's Quantum was created though sonifying data from the Large Haldron Colider (the piece was created as a result of Jobin's residency at CERN) ${ }^{7}$.

Conversely, Mira Calix's composition for Charlotte Jarvis' The Music of the Spheres ${ }^{8}$, will be encoded into DNA (a technique pioneered by her collaborator Dr Simon Goldman and the European Bioinformatics Institute), with the intention that the DNA be suspended in soap solution and blown into bubbles during a performance of the composition. Each of these approaches use sound to both capture and represent scientific data, though we might question the extent to which they operate pedagogically to communicate scientific knowledge. Javis' description of the prospective project, for example, states that it would be 'completely silent, but it would be full of music, bathing you in it, you'd walk out with it on your clothes and in your hair.' Indeed, further deliberation upon the aural dimension within science-engaged arts practice, might usefully throw into question what we mean by 'communicating' science - and what such 'science' might constitute. I approach these question, though, from another angle.

\section{Direction 2: mediating the biomedical}

As discussed above, both Going Dark and Autobiographer mediate at least part of their science through fictional character. We might ask whether this attachment to character (the bastion of the Aristolean tradition) within otherwise inter-medial performances, might be attributed to these performances' engagement with biomedical science. What I am suggesting is that biomedical science lends itself to both 'classic' and postdramatic dramaturgies, and, in particular, to the sort of intermediate forms described by Bartleet. Thus, some branches and discoveries of biomedical science prompt the new forms of dramaturgy required to capture 'the enigmatic and discontinuous qualities of the postclassical sciences' (Vanden Heuval, 2013, 367). At the same time, the practices and epistemological traditions of diagnosis, treatment and experience of disease find their dramatic mirror in Aristolean dramaturgy, centred as it is, upon the individual and played out through conflict (between health and disease, life and death). Thus, the closet conventionality that these three plays reveal in their recourse to character, despite their otherwise postdramatic qualities, might be at least partly attributed to the common interest of medicine and theatre in human experience.

Other projects presented at the Symposium also prioritized depictions of the subjective experience of those living with medical conditions over direct encounters with the relevant science, this time through presenting or involving actual patients as, or in place of, characters ${ }^{9}$. For example, in Must $^{10}$, a collaboration between the Clod Ensemble and Peggy Shaw, the latter examines her own body as a landscape, drawing from it her own medical and personal history. Brian Lobel's Fun with Cancer Patients is a participatory project in which teenagers created 'actions' depicting their experiences of living with cancer ${ }^{11}$. Elastic Theatre's Julius, a multi-disciplinary film-performance hybrid about the intrusive thoughts and ritual behaviour of obsessive compulsive disorder, had a

\footnotetext{
${ }^{6}$ http://www.tba21academy.org/about/

${ }^{7}$ http://www.gillesjobin.com/spip.php?article1134 and http://www.carlascaletti.com/Main/Sonification

8 http://www.artforeating.co.uk/restaurant/index.php?/project/music-of-the-spheres/

9 My use of the term 'patient' here is inaccurate (not all of these characters or people are under treatment), and somewhat inappropriate (because of its connotations of passivity). I retain it for convenience (it's shorter than 'those living with...') and in preference to terms such as 'sufferer' or 'vitmin' of disease.

${ }^{10}$ http://www.clodensemble.com/performance/must.htm

${ }^{11}$ http://www.blobelwarming.com/fun-with-cancer-patients/
} 
basis in its director's own experience of this condition ${ }^{12}$. Indeed, all of the projects drew on the experiences of what Kazuko Hohki referred to in her presentation as 'real people' with personal experience of pathology, whether or not this was mediated through a central character. In so doing, they followed a tradition established by Nell Dunn's Cancer Tales of engaging with 'ordinary people in the front line' (Dunn, 2002, 7), one that ascribes to these people the position of experts, and an authority at least equivalent to that attributed to the medical scientists. Indeed, I would go so far as to say that patients' own understandings of biomedical conditions takes on the status of a science.

This foregrounding of patients' experience of, rather than scientific facts about, specific pathologies could be construed as a critique of medical science as 'a form of control exerted on the human body', as Campos describes citing Foucault $(2013,300)$. Campos' recognition that the embodied nature of performance can constitute a site of resistance against the medical gaze is echoed by Symposium participants. Certainly, this stance is taken by Suzy Willson, co-director of the Clod Ensemble, who contrasted the notion of the 'poetic body' that she absorbed in her training at the Lecoq School in Paris, to the medical domain's 'fixed and compartmentalised' perception of the body. Her award-winning training scheme, Performing Medicine, seeks to counter what she regards as the 'institutional detachment' of medical practice so that its users might feel, as she put it, 'less brutalised by the medical encounter ${ }^{13}$. Likewise, Lobel commented on the culturally embedded hierarchies that position medical practitioners in roles akin to those of organised religion. Kazuko Hohki's Incontinental, a cabaret dealing with the social taboos of faecal incontinence, enacts a playful dismantling of this authority by including its scientist, Professor Alastair Forbes - who initially provides what he calls 'serious scientific lectures' within the performance - in the exuberant onstage action. ${ }^{14}$

Ultimately, however, I would suggest that this implicit critique of medical authority rarely negates the way in which medical science is simultaneously employed as a form of authority in these projects. Even though much of the scientific 'fact' is highly mediated and distilled, if not absent, in the performances themselves, the artists were invariably keen to emphasise the depth and accuracy of their research and their close involvement with medical experts in the making of the work. This might imply a rather classicist notion of science as a form of 'truth' (both Wilson and Espiner used this term), which we might be tempted to attribute to the fact that these projects are funded by the Wellcome Trust, a major research centre at the cutting edge of biomedical discovery and innovation. Indeed, the Arts Award stipulation that artists must work with an appropriate scientific 'expert' seems to embed the notion of science's authority from the start of the process. In practice, however, I would argue that the recourse to medical expertise, and to science as 'fact', may come from the artists themselves, a manifestation of their desire to validate the topical and social relevance of their work (or, cynic might say, the 'impact') at a time of economic constraint.

\section{Newer Directions}

The discussions above are best regarded as conversation-starters. There is much more to be said about the way in which sound functions within increasingly inter-medial science-engaged performance. And the tensions inherent in performances engaging with biomedical sciences, both in terms of their dramaturgical orientations, and the way they reflect social constructions of the role of art, science and medicine, merit lengthier consideration. Other projects and debates featured at the

\footnotetext{
${ }^{12}$ http://www.elastictheatre.com/productions/new-julius/

${ }^{13}$ http://performingmedicine.com/

${ }^{14}$ http://www.kazukohohki.com/kazuko/performance.html
} 
Splice Symposium and at Performing Science, would richly reward analysis and I hope that readers will discover their own 'new directions' among its contributors.

\section{FURTHER INFORMATION}

\section{Splice: intersecting performance/music/science/medicine}

Other contributors to Splice include: Kirsten Shepherd-Barr (Oxford University), Nicola Triscott (Arts Catalyst), Emma Wiles (Wellcome Trust), who mapped out the contemporary scene. Presentations engaging with aspects of theoretical physics came from: Alex Kelly (Third Angel) and Dr Simon Goodwin (astrophysics) on '300 Billion', Gilles Jobin (choreographer) on his residency at CERN, Dr David Berman (Queen Mary, Theoretical physics) on string theory and his collaborations with artists, and Prof Jean Dibble (University of Notre Dame, printmaking) whose print series 'The Life in Physics' responds to the unattainability of postclassical physics. Prof Nicola Shaughnessy and Anna Sadnicka (UCL Motor Neuroscience) dealt with the cognitive science and autism, and neuroscience of musicianship respectively. Dr Anna Farthing (Harvest Heritage Arts) described the use of performance in her work with medical museums. Sound projects were presented by Charlotte Javis, Tony Myatt and Simon Park. Nicola Triscott and Kate McGrath (Fuel Theatre) were the advisory committee.

Comprehensive coverage of the Splice Symposium, including recordings and images, is available at chimeranetwork.org/splice.

The Spice Symposium was a product on the Chimera Network, a research project exploring collaborative, creative and compositional strategies employed in the making of science-engaged performance and sound projects. In addition to the Splice Symposium, Chimera Network activities included the creation of a performance engaging with both the science and subjective experience of leukaemia treatment (Bloodlines), workshops and training events. Chimera was supported by the Arts and Humanities Research Council. www.chimeranetwork.org

\section{Dialogues Across Cultures: the Performing Science Conference}

Other contributors to Performing Science included Nicola Shaughnessy, Ellen Dowell (Imperial College London), Liam Jarvis (Analogue), Jack Lowe (Curious Directive), Nicholas Arnold (Adam Mickewicz University), Mario Montenegro (Marionet Theatre Company, Portugal), Susan Gray, Katrine Antonsen (Norwegian University of science and Technology), Josh Judd (Northampton), Prof Eva-Sabine Zehelein (University of Regensburg), Philip Ball, Hansjorg Schmidt, David Jackson (Birmingham City University), David Cahill Roots (Wellcome Trust), Kate McGrath (Fuel Theatre), Prof Brian Schartz (Brooklyn College, USA), Paul Johnson (University of Woverhampton), Dr Cheryl Faraone and Pro Steve Abbott (Middlebury College, USA), Tim Senior (University of Bristol), Darren Tunstall (University of Central Lancashire), Vivienne Glance (Western University, Australia), Steve Walters (University of East Anglia), Simon Watt (Ready, Steady, Science), Nigel Townsend ( $Y$ Touring), Dr Chretien Schouteten, Dr Gianna Bouchard (Anglia Ruskin University) and Dr Laura Purcell Gates (Bath Spa University). The conference featured workshops with Amanda Couch (University of the Creative Arts), Karen Wood (University of Wolverhampton) and Katherine fry (Queen Mary, University of London). Three productions were shown: Jack Klaff's The Whole Shebang, the Chimera Network's Bloodlines, and Djerassi's Foreplay.

Dialogues Across Cultures: The Performing Science Conference was convened by director/producer Andy Jordan, Senior Lecturer at The University of Lincoln's School of Performing Arts. Through his company, Andy Jordan Productions, Andy has directed the UK 
premiere's of all of Carl Djerassi's plays. Alex Mermikides, Robert Marc Friedman, Darren Tunstall and Paul Johnson formed the advisory committee.

\section{References}

Bartleet, Carina. 2013. Performing Science (Not Ethics) in Analogues 2410 Objects. Interdisciplinary Science Reviews 38, 4: 351-64

Campos, Liliana. 2013. Science in Contemporary British Theatre: a Conceptual Approach Interdisciplinary Science Reviews 38, 4: 295-305

Dunn, Nell. 2002. Cancer Tales. Oxon: Amber Lane Press

Dyson, Frances. 2009. Sounding New Media: Immersion and Embodiment in Arts and Culture. Berkeley, Los Angeles, London: University of California Press

Kendrick, Lynne and David Roesner. Eds. 2011. Theatre Noise: The Sound of Performance. Newcastle upon Tyne: Cambridge Scholars Press

Knight, David. 2002. Scientific Lectures: A History of Performance. Interdisciplinary Science Reviews 27, 3: 217:224

Roesner, David and Matthias Rebstock. Eds. 2012. Composed Theatre: Aesthetics, Practices, Processes. Bristol and Chicago: Intellect Press

Shepherd-Barr, Kirsten. 2006. Science on Stage: From Doctor Faustus to Copenhagen. Princeton and Oxford: Princeton University Press.

Vanden Heuval, Mike. 2013. The Acceptable Face of the Unintelligible - Intermediality and the Science Play. Interdisciplinary Science Reviews 38, 4: 365-379. 